\title{
Estimation of Probable Maximum One Day Duration Rainfall for Khurda Region
}

\author{
Geetanjali Dhupal $^{1 *}$ and Sidhartha Sekhar Swain ${ }^{2}$ \\ ${ }^{1}$ Centurion University of Technology and Management, $R$ Sitapur, \\ Paralakhemundi, Odisha, 761211, India \\ ${ }^{2}$ Indian Agricultural Research Institute, Division of Agricultural Engineering, \\ New Delhi, 110012, India \\ *Corresponding author
}

A B S T R A C T

\begin{tabular}{|l|}
\hline Ke y w o r d s \\
Probable maximum \\
precipitation, \\
Return period, \\
Probability \\
distribution, \\
Standard deviation \\
\hline Article Info \\
\hline $\begin{array}{l}\text { Accepted: } \\
18 \text { April } 2020 \\
\text { Available Online: } \\
\text { 10 May } 2020\end{array}$ \\
\hline
\end{tabular}

\begin{abstract}
The knowledge of probable maximum one day rainfall for a given region corresponding to return periods varying from 2 to 100 years is essential for crop planning and designs of minor and major hydraulic structures. The probability analysis for maximum one day rainfall of Khurda region is done by different probability distribution methods (log normal 3-parameter, pearson method, log pearson, weibull, generalized pare to distribution and log normal) by taking the rainfall data of 25 years(1991-2015) through FLOOD - frequency analysis software. Amongst them, log-normal 3parameter method was found to be best fit based on chi-square and RMSE values 4.5 and 0.03328 respectively. The rainfall at $90 \%, 75 \%, 50 \%, 25 \%$ and $10 \%$ probability levels are determined. The plotted position of maximum one day precipitation was also tested through Chow method. The designed return period is calculated through Gumbel's equation. The observed one day maximum rainfall during period of analysis is $400.3 \mathrm{~mm}$ with standard deviation and co-efficient of variation $71.06 \mathrm{~mm}$ and $0.552 \mathrm{~mm}$ respectively. The values of maximum precipitation by log-normal 3parameter method and Chow frequency factor method are very close to each other and from these two methods, either can be implemented for design of different soil and water conservation structures.
\end{abstract}

\section{Introduction}

The knowledge of probable maximum rainfall for a given region or area is a pre requisite for planning and designs of structures such as check dams, storage reservoirs, drainage works, irrigation tanks, building, highway bridges etc. Also a high density of rainfall causes large scale flooding, claiming several lives and causing property damage on enormous scale. Therefore accurate estimates of maximum rainfall should be essential for a hydrologist to prevent re-recoverable losses.

Hydrologist use the probable maximum rainfall magnitude and its spatial and temporal distributions to calculate the probable maximum flood, which is one of several conceptual flood events used in the design of hydrological structures, for 
maximum reliability and safety. Maximum one day rainfall can be used for design of overflow arrangement of conservation structures for study of flood frequency, drought analysis and analysis of probable rainfall, it's occurrence and distribution throughout the year are important for every cultivator, both for deciding the cropping pattern and for providing irrigation. Annual daily maximum rainfall corresponding to return periods varying from 2 to 100 years is used by design engineers and hydrologists for economic planning, and design of minor and major hydraulic structures.

Therefore in the present study, the effort has been made to estimate the maximum one day rainfall for different return periods, which can be used for designing of various water harvesting structures in the study area.

\section{Review of literature}

The study was undertaken by Singh et al., (2013) on "Estimation of probable maximum precipitation for one day duration in Jhalarapatan region of Rajasthan". According to them, daily rainfall data for a period of 51 years (1961-2011) were analyzed for estimation of probable maximum precipitation based on appropriate frequency factor. The maximum one day rainfall for different return periods were also estimated by Hershfield technique and Gumbel's theory of extreme values which could be useful in appropriate designs of soil and water conservation irrigation $\&$ drainage plans.

"Rainfall probability analysis for crop planning in Kandhamal district" was undertaken by Subudhi et al., (2012). Estimation was done by different distribution and chi square test was made. The aim was for crop planning by storing excess run off water in some storage structures so as to use it for irrigating post-monsoon crops.

\section{Materials and Methods}

\section{Site selection}

Khurda district with an area of $2813 \mathrm{sq} \mathrm{km}$ is bounded between latitudes $19^{\circ} 40^{\prime} \mathrm{N}$ and $20^{\circ}$ $27^{\prime} \mathrm{N}$ and longitudes $84^{\circ} 56^{\prime} \mathrm{E}$ and $86^{\circ} 05^{\prime} \mathrm{E}$. The district is drained by a number of streams which are mostly tributaries and distributaries of the river Mahanadi and a few other streams discharging into lake Chilika. The normal annual rainfall is $1449.1 \mathrm{~mm} \&$ the annual average rainfall is $1436.1 \mathrm{~mm}$.

\section{Rainfall data}

The data are collected from meteorological department, Bhubaneswar which is coming under khurda district, for this study. Rainfall data for 25 years from 1991 to 2015 are collected for the presented study to make rainfall forecasting through different methods. The rainfall data are arranged in descending order and corresponding rank no is given. Applying weibull's technique probability of different return period is calculated.

\section{Estimation of parameters}

For parameter estimation, the generalized probability weighted moments is considered. Among the available goodness-of-fit tests, Chi-square test has been used for the present study.

\section{Probability distribution}

The data is fed into the Excel spreadsheet, where it is arranged in a chronological order and the Weibull plotting position formula is then applied. The Weibull plotting position formula is given by

$p=\frac{m}{N+1}$ 
where $m=$ rank number

$N=$ number of years

$\mathrm{P}=$ probability

The recurrence interval is given by

$T=\frac{1}{p}=\frac{N+1}{m}$

The values are then subjected to various probability distribution functions namelynormal, log-normal (2-parameter), log-normal (3-parameter), gamma, generalized extreme value, Weibull, generalized Pareto distribution, Pearson, log-Pearson type-III and Gumbel distribution. The probability distribution functions are described as follows:

\section{Normal distribution}

The probability density is

$p(x)=(1 / \sigma \sqrt{2 \pi}) e^{-(x-\mu)^{2} / 2 \sigma^{2}}$

where $x$ is the variate, ${ }^{\mu}$ is the mean value of variate and ${ }^{\sigma}$ is the standard deviation. In this distribution, the mean, mode and median are the same. The cumulative probability of a value being equal to or less than $x$ is $p(x \leq)=1 / \sigma \sqrt{2 \pi} \int_{-\infty}^{x} e^{-(x-\mu)^{2} / 2 \sigma^{2}} d x$

This represents the area under the curve between the variates of ${ }^{-\infty}$ and $^{x}$.

\section{Log-normal (2-parameter) distribution}

The probability density is

$p(x)=\left(1 / \sigma_{y} e^{y} \sqrt{2 \pi}\right) e^{-\left(y-\mu_{y}\right)^{2} / 2 \sigma_{y}}$

where $y=\ln x$, where $x$ is the variate, ${ }^{\mu} y$ is the mean of $y$ and $\sigma_{y}$ is the standard deviation of $y$.

\section{Log-normal (3-parameter) distribution}

A random variable $X$ is said to have threeparameter log-normal probability distribution if its probability density function (pdf) is given by :

$f(x)=\left\{\frac{1}{(x-\lambda) \sigma \sqrt{2 \pi}} \exp \left\{-\frac{1}{2}\left(\frac{\log (x-\lambda)-\mu}{\sigma}\right)\right\}, \lambda<x<\infty, \mu>0, \sigma>0\right\}$

where ${ }^{\mu, \sigma}$ and $\lambda$ are known as location, scale and threshold parameters, respectively.

\section{Gamma distribution}

Probability density function of this distribution is given by:

$p(x)=x^{a} e^{-x / b / b(a+1) \Gamma(a+1)}$

with $b>0, a>-1$ for $x=0$ and $p(x)=0$ for $\leq_{0}$; where $a$ \& $b$ are constants and $\Gamma(a+1)=a$ ! is a gamma function. The cumulative probability being equal to or less than $x(<\infty)$ is known as incomplete gamma function.

The statistical parameters are Mean $=b(a+1)$ and variance $={ }^{b^{2}}(a+1)$

\section{Pearson distribution}

The general and basic equation to define the probability density function of a Pearson distribution

$p(x)=e \int_{-\infty}^{x} \frac{a+x}{b_{0}+b_{1} x+b_{2} x^{2}} d x$

where $a, b_{0}, b_{1}$ and $b_{2}$ are constants. 
The criteria for determining types of distribution are $\beta_{1}, \beta_{2}$ and $k$ where

$\beta_{1}=\frac{\mu_{3}^{2}}{\mu_{2}^{3}}$

$\beta_{2}=\frac{\mu_{4}}{\mu_{2}^{2}}$

$k=\frac{\beta_{1}\left(\beta_{2}+3\right)^{2}}{4\left(4 \beta_{2}-3 \beta_{1}\right)\left(2 \beta_{2}-3 \beta_{1}-6\right)}$

Where $\mu_{2}, \mu_{3}$ and $\mu_{4}$ are second, third and fourth moments about the mean.

When $\beta_{1}=0, \beta_{2}=3$ and $k=0$, the Pearson distribution is identical to the normal distribution.

\section{Type-I distribution}

For Type-I, $\mathrm{k}<0$. Its probability density is

$p(x)=p_{0}\left(1+\frac{x}{a_{1}}\right)^{m_{1}}\left(1-\frac{x}{a_{2}}\right)^{m_{2}}$

where $m_{1} / a_{1}=m_{2} / a_{2}$ and the origin is at the mode.

The values of $m_{1}$ and $m_{2}$ are given by $m_{1}$ or $\left.m_{2}\right)=\frac{1}{2}\left[r-2 \pm r(r+2) \frac{\sqrt{\mu_{2} \beta_{1}}}{2\left(a_{1}+a_{2}\right)}\right]$

when $\mu_{2}$ is positive, $m_{2}$ is the positive root and $m_{1}$ is the negative root and

$r=\frac{6\left(\beta_{2}-\beta_{1}-1\right)}{6+3 \beta_{1}-2 \beta_{2}}$

$a_{1}+a_{2}=1 / 2 \sqrt{\mu_{2}\left[\beta_{1}(r+2)^{2}+16(r+1)\right]}$
And $p_{0}=\frac{N}{a_{1}+a_{2}} \frac{m_{1}{ }^{m_{1}} m_{2} m_{2}}{\left(m_{1}+m_{2}\right)^{\left(m_{1}+m_{2}\right)}} \frac{\Gamma\left(m_{1}+m_{2}+2\right)}{\Gamma\left(m_{1}+1\right) \Gamma\left(m_{2}+1\right)}$

where $\mathrm{N}$ is the total frequency.

\section{Type-III distribution}

For Type-III distribution

$k=\infty$ or $2 \beta_{2}=3 \beta_{1}+6$

The probability density with the origin at mode is $p(x)=p_{0}(1+x / a)^{c} e^{-c x / a}$

Where $c=\frac{4}{\beta_{1}}-1$

$a=\frac{c}{2} \frac{\mu_{g}}{\mu_{2}} \quad p_{0}=\frac{N c^{c+1}}{a e^{c} \Gamma(c+1)}$

\section{Log-Pearson Type III distribution}

In this the variate is first transformed into logarithmic form (base 10) and the transformed data is then analyzed. If $X$ is the variate of a random hydrologic series, then the series of $Z$ variates, where, $z=\log x$ are first obtained.

For this $\mathrm{z}$ series, for any recurrence interval $T$ and the coefficient of skew $C_{\Xi^{3}} \quad \sigma_{z}=$ standard deviation of the $Z$ variate sample

$$
\sigma_{z}=\sqrt{\sum(z-\bar{z})^{2} /(N-1)}
$$

And $C_{s}=$ coefficient of skew of variate $Z$

$C_{s=} \frac{N \sum(z-\vec{z})^{s}}{(N-1)(N-2) \sigma_{z}{ }^{s}}$

$\bar{z}=$ mean of $z$ values,$N=$ sample size $=$ number of years of record 


\section{Generalized pareto distribution}

The family of generalized Pareto distributions (GPD) has three parameters $\mu, \sigma$ and $\xi$.

The cumulative distribution function is $F_{(s, \mu, \sigma)}(x)=\left\{\begin{array}{cc}1-\left(1+\frac{\xi(x-\mu)}{\sigma}\right)^{\frac{-1}{\xi}} \text { for } \xi \neq 0 \\ 1-\exp \left(-\frac{x-\mu}{\sigma}\right) & \text { for } \xi=0\end{array}\right\}$ for $x \geq \mu$ when $\xi \geq 0$ and $x \leq \mu-\frac{\sigma}{\xi}$ when $\xi<0{ }^{\text {where }}{ }^{\mu \in \mathbb{R}}$ is the location parameter, $\sigma>0$ the scale parameter and $\xi \in \mathbb{R}$ the shape parameter.

The probability density function is

$$
\begin{aligned}
& f_{(\xi, \mu, \sigma)}(x)=\frac{1}{\sigma}\left(1+\frac{\xi(x-\mu)}{\sigma}\right)^{\left(-\frac{1}{\xi}-1\right)} \text { or } \\
& f_{(\xi, \mu, \sigma)}(x)=\frac{\sigma^{\frac{1}{\xi}}}{(\sigma+\xi(x-\mu))^{\left(\frac{1}{\xi}+1\right)}} \\
& \text { for }^{x \geq \mu} \text {, and } x \leq \mu-\frac{\sigma}{\xi} \text { when } \xi<0
\end{aligned}
$$

\section{Generalized extreme value distribution}

Generalized extreme value distribution has cumulative distribution function

$F(x ; \mu, \sigma, \xi)=\frac{1}{\sigma}\left[1+\xi\left(\frac{x-\mu}{\sigma}\right)\right]^{\left(\frac{1}{\xi}-1\right)} \exp \left\{-\left[1+\xi\left(\frac{x-\mu}{\sigma}\right)^{\frac{-1}{\xi}}\right]\right\}$

For $1+^{\xi(x-\mu) / \sigma>0}$, where ${ }^{\mu \in \mathbb{R}}$ is the location parameter, $\sigma>0$ the scale parameter and $\xi \in \mathbb{R}$ the shape parameter. The density function is, consequently $f(x ; \mu, \sigma, \xi)=\frac{1}{\sigma}\left[1+\xi\left(\frac{x-\mu}{\sigma}\right)\right]^{\left(\frac{-1}{\xi}-1\right)} \exp \left\{-\left[1+\xi\left(\frac{x-\mu}{\sigma}\right)^{\frac{-1}{\xi}}\right]\right\}$

again, for ${ }^{1+} \xi(x-\mu) / \sigma>0$

\section{Gumbel's method}

The probability of occurrence of an event equal to or larger than a value $x_{0}$ is

$P\left(X \geq x_{0}\right)=1-e^{-e^{-y}}$

in which $y$ is a dimensionless variable and is given by

$y=\alpha(x-a) \quad a=\bar{x}-0.45005 \sigma_{x}$

Thus

$$
y=\frac{1.2825(x-\bar{x})}{\sigma_{x}}+0.577
$$

where ${ }^{\bar{x}}=$ mean and ${ }^{\sigma_{x}}=$ standard deviation of the variate $X$. In practice it is the value of $X$ for a given $P$ that is required and such Eq. (i) is transposed as

$y_{p}=-\ln [-\ln (1-P)]$

Noting that the return period $T=1 / P$ and designating $y_{T}=$ the value of $y$, commonly called the reduced variate, for a given $T$

$y_{T}=-\left[\ln \cdot \ln \frac{T}{T-1}\right]$

or

$y_{T}=-\left[0.834+2.303 \log \log \frac{T}{T-1}\right]$

Now rearranging Eq. (i), the value of the variate $\mathrm{X}$ with a return period $T$ is

$x_{T}=\bar{x}+K \sigma_{x}$
$K=\frac{\left(y_{T}-0.577\right)}{1.2825}$ where 
The above equations constitute the basic Gumbel's equations and are applicable to an infinite sample size (i.e. $N \rightarrow \infty$ ).

\section{Weibull distribution}

The two-parameter version of this distribution has the density function

$f(x)=\frac{\alpha}{\beta}\left(\frac{x}{\beta}\right)^{\alpha-1} \exp \left(-\left(\frac{x}{\beta}\right)^{\alpha}\right)$

The Weibull distribution is defined for $x>0$, and both distribution parameters $\left({ }^{\alpha}\right.$-shape, ${ }^{\beta}$ scale) are positive. The two-parameter Weibull distribution can be generalized by adding the location (shift) parameter ${ }^{\gamma}$ :

$f(x)=\frac{\alpha}{\beta}\left(\frac{x-\gamma}{\beta}\right)^{\alpha-1} \exp \left(-\left(\frac{x-\gamma}{\beta}\right)^{\alpha}\right)$

In this model, the location parameter ${ }^{\gamma}$ can take on any real value, and the distribution is defined for $x>y$.

The various parameters like mean, standard deviation, RMSE value, Chi-square values were obtained and noted for different distributions. For generalized extreme value and generalized Pareto distribution the other parameters like shape parameter ${ }^{\xi}$, scale parameter ${ }^{\sigma}$ and location parameter ${ }^{\mu}$ are also noted for further calculation. Similar procedure is followed for the seasonal, annual and pentad analysis.

\section{Goodness-of-fit test}

Chi-square test of goodness of fit of observed values is calculated by following equation:

$\chi_{c}^{2}=\sum_{i=1}^{K} \frac{\left(O_{i}-E_{i}\right)^{2}}{E_{i}}$
Where, $\mathrm{K}$ is the number of class interval, $O_{i}$ and $E_{i}$ are the observed and expected rainfall values in the $i^{\text {th }}$ class, respectively. The distribution with least sum of $\chi_{c}^{2}$ values will be adjudged the best. Apart from Chisquare test other goodness-of-fit tests like Anderson-Darling test (AD) have been used by Sharda and Das (2005).

\section{Determination of different parameters}

$$
\mathrm{S}=\left[\frac{\sum x^{2}-\left(\frac{\sum x^{2}}{n}\right)}{n-1}\right]^{\frac{1}{2}}
$$

Where $\mathrm{x}=$ measured value(rainfall) $\mathrm{n}=$ number of years taken

The coefficient of variation is $c_{v=\frac{s}{x^{\prime}}}$

$$
s^{3}=c_{v}^{3}\left(x^{-3}\right) .
$$

$C_{s=}$

$\left(\frac{n}{(n-1)(n-2)}\right)^{\left(\frac{\sum x^{\mathrm{s}}}{n}\right)-\frac{3\left(x^{-}\right)\left(\sum x^{2}\right)}{n}+2(x)^{3} / S_{S^{3}}}$

Where $C_{s=\text { coefficient of skew }}$

Skewness coefficient is the method that refers to the amount of symmetry or asymmetry of a distribution.

The rainfall at $90 \%, 75 \%, 50 \%, 25 \%$ and $10 \%$ probability levels are determined. The distribution "best" fitted to the data is noted down in a tabulated form .

In the present study, the parameters of distribution for the different distributions have been estimated by FLOOD-flood frequency analysis software. The rainfall data is the input to the software programme 


\section{Results and Discussion}

\section{Maximum one day rainfall}

Rainfall data for 25 years (1991-2015) was collected. The maximum one day rainfall of different years was found out and is plotted in Fig. 1. It is observed from the figure that, the maximum one day rainfall of $400.3 \mathrm{~mm}$ is observed in the year 1999. The minimum $(58.2 \mathrm{~mm})$ is found in the year 1998 .

\section{Probability analysis of rainfall}

The rainfall data of 25 years (1991-2015) were analysed by different methods (Log normal 3 parameter, pearson, Log-pearson, Weibill, Generalized pareto distribution and log normal)and are given in table 1 .

From above table the variation of rainfall is very less between log normal and log normal 3-parameter distribution. The variation between person method and log-pearson method is also $1-1.5 \mathrm{~mm}$. Weibill and Generalized pareto distribution having more variation with different probability.

The chi-square values (both computed and tabulated values) and also the RMSE (Root Means Square Error) are also given in the table 2. From the table it is observed that the rainfall at different probabilities was considered based on observing the minimum chi square value. From the table it is found that the chi-square value was minimum with $\log$-normal 3 parameter distribution.

The rainfall at different probability of accidence with this (log -normal 3-parameter) method is given in table 3 . along with the return period. So, the rainfall at different probabilities with log-normal 3 parameter distribution was considered in the present context. It is observed that from the table that rainfall is decreasing as probability is increasing. Further the plotting position of rainfall at different probabilities estimated following the Chow (1951) method considering the frequency factor ' $k$ '. The frequency factor, skewness coefficient, coefficient of variation and corresponding probable maximum rainfall were determined using equations given in chapter-iv. The observed one day maximum one day rainfall during period of analysis is $400.3 \mathrm{~mm}$ with standard deviation and co-efficient of variation $71.06 \mathrm{~mm}$ and $0.552 \mathrm{~mm}$ respectively (Table 4).

The theoretical log-probability frequency factor for different return period and probability can be calculated considering $\mathrm{C}_{\mathrm{V}}$ and $\mathrm{C}_{S}$ value, the $\log$ probability frequency factor(k) can be calculated for different probability and given by table 5 .

Referring eq no (a) and considering the frequency factor and the rainfall values at different probabilities with return period is given in table 6 .

Comparing the two method i.e Gumbel method and log normal 3-parameter test method, table (3 and 6) the rainfall at different probabilities and return period at par.

\section{Regression analysis of one day maximum probable rainfall}

Therefore in the present study the mathematical relationship between the rainfall and return period was considered for both the methods and the values are given in table.

\section{Analysis of rainfall through log-normal 3- parameters distribution}

The values are plotted in graph Fig. 2. referring table 3 shows relationship between rainfall and return period. The equation obtained is given as follows: 
Equation is

$\mathrm{Y}=66.057 \ln (\mathrm{x})+63.181$

where $R^{2}=0.9992$

$\mathrm{X}=$ return period, year and $\mathrm{Y}=$ one day maximum rainfall, $\mathrm{mm}$

Using above equation the expected maximum one day rainfall for different return periods for the study area is shown in the table 7. The expected maximum one day rainfall for 50 and 100 years return period is 321.59 and $367.38 \mathrm{~mm}$ respectively. A maximum of $110.62 \mathrm{~mm}$ rainfall is expected to occur at every 2 years (Table no 3 ). It is generally recommended that 2-100 years is sufficient return period for soil and water conservation measures, construction of dams, irrigation and drainage works (Fig. 3).

Table.1 Rainfall at different probability of exceedance with different distribution

\begin{tabular}{|c|c|c|c|c|c|c|c|c|}
\hline \multirow{2}{*}{$\begin{array}{l}\text { Sl. } \\
\text { No. }\end{array}$} & \multirow[t]{2}{*}{ Methods } & \multicolumn{5}{|c|}{ Rainfall(mm) at different probability levels } & \multirow{2}{*}{$\begin{array}{l}\text { Computed chi } \\
\text { square value }\end{array}$} & \multirow{2}{*}{$\begin{array}{l}\text { Tabulated chi } \\
\text { square value }\end{array}$} \\
\hline & & $90 \%$ & $75 \%$ & $\mathbf{5 0 \%}$ & $25 \%$ & $10 \%$ & & \\
\hline 1 & Log-normal 3 parameter & 66.16 & 82.67 & 110.62 & 154.08 & 213.54 & 4.5 & 4.64 \\
\hline 2 & Pearson method & 69.03 & 88.75 & 110.99 & 159.56 & 215.01 & 2.1 & 2.41 \\
\hline 3 & Log-pearson & 69.99 & 89.03 & 112.76 & 160.05 & 214.6 & 1.16 & 1.39 \\
\hline 4 & Weibill & 68.1 & 87.4 & 111.8 & 158.6 & 216.6 & 10.76 & 11.3 \\
\hline 5 & $\begin{array}{l}\text { Generalized } \\
\text { distribution }\end{array}$ & 67.05 & 85.55 & 114.67 & 162.78 & 219.45 & 3.56 & 4.61 \\
\hline 6 & Log-normal & 66.47 & 82.97 & 111 & 154.99 & 213.89 & 4.52 & 4.64 \\
\hline
\end{tabular}

Table.2 RMSE value and mean absolute error for different probability distribution

\begin{tabular}{|l|l|l|l|}
\hline Sl. no & \multicolumn{1}{|c|}{ Probability Distribution } & \multicolumn{1}{|c|}{ RMSE value } & Mean absolute error \\
\hline $\mathbf{1}$ & Log pearson(mom) & 0.03328 & 0.02682 \\
\hline $\mathbf{2}$ & Log normal 3 parameter(mom) & 0.03866 & 0.03209 \\
\hline $\mathbf{3}$ & Generalized extreme value(mom1) & 0.04108 & 0.03262 \\
\hline $\mathbf{4}$ & Log normal(mom) & 0.04724 & 0.03794 \\
\hline $\mathbf{6}$ & Generalized pareto(mom) & 0.05987 & 0.05162 \\
\hline $\mathbf{7}$ & Pearson(mom) & 0.06197 & 0.05184 \\
\hline
\end{tabular}

Table.3 Rainfall at different probability and return period with log-normal 3- parameter

\begin{tabular}{|l|c|c|c|}
\hline Sl. No & Probability(\%) & Rainfall $(\mathbf{m m})$ & Return period (years) \\
\hline $\mathbf{1}$ & 5 & 262.32 & 20 \\
\hline $\mathbf{2}$ & 10 & 213.54 & 10 \\
\hline $\mathbf{3}$ & 20 & 168.16 & 5 \\
\hline $\mathbf{4}$ & 25 & 154.08 & 4 \\
\hline $\mathbf{5}$ & 30 & 142.68 & 3.33 \\
\hline $\mathbf{6}$ & 40 & 124.74 & 2.5 \\
\hline $\mathbf{7}$ & 50 & 110.62 & 2 \\
\hline $\mathbf{8}$ & 60 & 98.65 & 1.66 \\
\hline $\mathbf{9}$ & 70 & 87.87 & 1.42 \\
\hline $\mathbf{1 0}$ & 75 & 82.67 & 1.33 \\
\hline $\mathbf{1 1}$ & 80 & 77.45 & 1.25 \\
\hline $\mathbf{1 2}$ & 90 & 66.16 & 1.11 \\
\hline
\end{tabular}


Table.4 Different rainfall characteristics

\begin{tabular}{|l|l|l|}
\hline SI no & Parameters & Computed value \\
\hline $\mathbf{1}$ & Average one day maximum rainfall $(\mathrm{mm})$ & 128.636 \\
\hline $\mathbf{2}$ & Standard deviation $(\mathrm{mm})$ & 71.06 \\
\hline $\mathbf{3}$ & Coefficient of variation $\left(C_{\mathrm{v}}\right)$ & 0.552 \\
\hline $\mathbf{4}$ & Skewness coefficient $\left(c_{s}\right)$ & 0.102 \\
\hline $\mathbf{5}$ & Highest observed rainfall $(\mathrm{mm})$ & 400.3 \\
\hline
\end{tabular}

Table.5 Different probability and return period for different frequency factor

\begin{tabular}{|l|l|l|l|}
\hline SI no & $\begin{array}{l}\text { Probability } \\
(\mathbf{p})(\mathbf{\%})\end{array}$ & $\begin{array}{l}\text { Return } \\
\text { period(t) (year) }\end{array}$ & Frequency factor(k) \\
\hline $\mathbf{1}$ & 1 & 100 & 3.45 \\
\hline $\mathbf{2}$ & 5 & 20 & 1.89 \\
\hline $\mathbf{3}$ & 20 & 5 & 0.63 \\
\hline $\mathbf{4}$ & 50 & 2 & -0.17 \\
\hline $\mathbf{5}$ & 99 & 1.01 & -1.22 \\
\hline
\end{tabular}

Table.6 Rainfall at different reurn period with Gumbel method

\begin{tabular}{|l|l|l|l|}
\hline Sl no & Frequency factor & Rainfall & Return period \\
\hline $\mathbf{1}$ & 3.45 & 373.79 & 100 \\
\hline $\mathbf{2}$ & 1.89 & 262.93 & 20 \\
\hline $\mathbf{3}$ & 0.63 & 173.40 & 5 \\
\hline $\mathbf{4}$ & -0.17 & 116.55 & 2 \\
\hline $\mathbf{5}$ & -1.22 & 41.94 & 1.01 \\
\hline
\end{tabular}

Table.7 Maximum one day rainfall under different return period

\begin{tabular}{|l|c|c|}
\hline Sl no & Return period(year) & Estimated maximum one day rainfall(mm) \\
\hline $\mathbf{1}$ & 2 & 108.96 \\
\hline $\mathbf{2}$ & 5 & 169.49 \\
\hline $\mathbf{3}$ & 10 & 215.28 \\
\hline $\mathbf{4}$ & 15 & 242.06 \\
\hline $\mathbf{5}$ & 20 & 261.07 \\
\hline $\mathbf{6}$ & 25 & 275.81 \\
\hline $\mathbf{7}$ & 30 & 287.85 \\
\hline $\mathbf{8}$ & 40 & 306.85 \\
\hline $\mathbf{9}$ & 50 & 321.59 \\
\hline $\mathbf{1 0}$ & 60 & 333.64 \\
\hline $\mathbf{1 1}$ & 70 & 343.82 \\
\hline $\mathbf{1 2}$ & 80 & 352.64 \\
\hline $\mathbf{1 3}$ & 90 & 360.42 \\
\hline $\mathbf{1 4}$ & 100 & 367.38 \\
\hline
\end{tabular}


Table.8 Maximum one day rainfall under different return period by Gumbel's method

\begin{tabular}{|l|c|c|}
\hline Sl. no & Return period(year) & $\begin{array}{c}\text { Estimated maximum one day } \\
\text { rainfall(mm) }\end{array}$ \\
\hline $\mathbf{1}$ & 2 & 103.73 \\
\hline $\mathbf{2}$ & 5 & 167.67 \\
\hline $\mathbf{3}$ & 10 & 216.04 \\
\hline $\mathbf{4}$ & 15 & 244.34 \\
\hline $\mathbf{5}$ & 20 & 264.41 \\
\hline $\mathbf{6}$ & 25 & 279.98 \\
\hline $\mathbf{7}$ & 30 & 292.70 \\
\hline $\mathbf{8}$ & 40 & 312.78 \\
\hline $\mathbf{9}$ & 50 & 328.35 \\
\hline $\mathbf{1 0}$ & 60 & 341.07 \\
\hline $\mathbf{1 1}$ & 70 & 351.83 \\
\hline $\mathbf{1 2}$ & 80 & 361.15 \\
\hline $\mathbf{1 3}$ & 90 & 369.37 \\
\hline $\mathbf{1 4}$ & 100 & 376.72 \\
\hline
\end{tabular}

Table.9 Probable maximum one day rainfall for different structures by chow and log normal 3parameter

\begin{tabular}{|c|c|c|c|c|c|}
\hline \multirow[t]{2}{*}{$\begin{array}{l}\text { Sl. } \\
\text { No. }\end{array}$} & \multirow[t]{2}{*}{$\begin{array}{l}\text { Type of soil and water } \\
\text { conservation structure }\end{array}$} & \multirow[t]{2}{*}{$\begin{array}{l}\text { Return period } \\
\text { (Year) }\end{array}$} & \multirow[t]{2}{*}{$\begin{array}{l}\text { Probability } \\
(\%)\end{array}$} & \multicolumn{2}{|c|}{$\begin{array}{l}\text { Probable maximum one day } \\
\text { Rainfall }(\mathbf{m m})\end{array}$} \\
\hline & & & & Chow & $\begin{array}{l}\text { Log-normal } 3 \\
\text { parameter }\end{array}$ \\
\hline 1 & $\begin{array}{l}\text { Terrace outlets and } \\
\text { vegetated water ways }\end{array}$ & 10 & 10 & 216 & 216 \\
\hline 2 & Field diversions & 15 & 6.66 & 245 & 243 \\
\hline 3 & 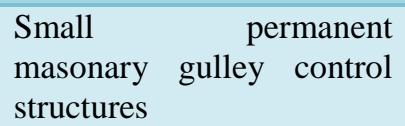 & $10-15$ & $10-6.66$ & $216-245$ & $216-243$ \\
\hline 4 & Stock water dams & 25 & 4 & 280 & 276 \\
\hline 5 & $\begin{array}{l}\text { Earth fill dams-storage } \\
\text { having natural spillways }\end{array}$ & $25-50$ & $4-2$ & $280-329$ & $276-322$ \\
\hline 6 & $\begin{array}{l}\text { Storage and diversion } \\
\text { dams having spillways }\end{array}$ & $50-100$ & $2-1$ & $329-377$ & $322-368$ \\
\hline
\end{tabular}

Table.10 Comparison of maximum precipitation by chow and log-normal 3-parameter method

\begin{tabular}{|c|c|c|c|}
\hline SI no. & $\begin{array}{l}\text { Type of soil and water } \\
\text { conservation structure }\end{array}$ & $\begin{array}{l}\text { Maximum precipitation by log- } \\
\text { normal 3-parameter test }\end{array}$ & $\begin{array}{l}\text { Maximum recipitation by } \\
\text { Chow method }\end{array}$ \\
\hline 1 & $\begin{array}{l}\text { Terrace outlet and vegetated } \\
\text { water ways }\end{array}$ & 216 & 216 \\
\hline 2 & Field diversions & 243 & 245 \\
\hline 3 & $\begin{array}{l}\text { Small permanent masonary gully } \\
\text { control structures }\end{array}$ & $216-243$ & $216-245$ \\
\hline 4 & Stock water dams & 276 & 280 \\
\hline 5 & $\begin{array}{l}\text { Earth fill dams-storage having } \\
\text { natural spillways }\end{array}$ & $276-322$ & $280-329$ \\
\hline 6 & $\begin{array}{l}\text { Storage and diversion dams } \\
\text { having spillways }\end{array}$ & $322-368$ & $329-377$ \\
\hline
\end{tabular}




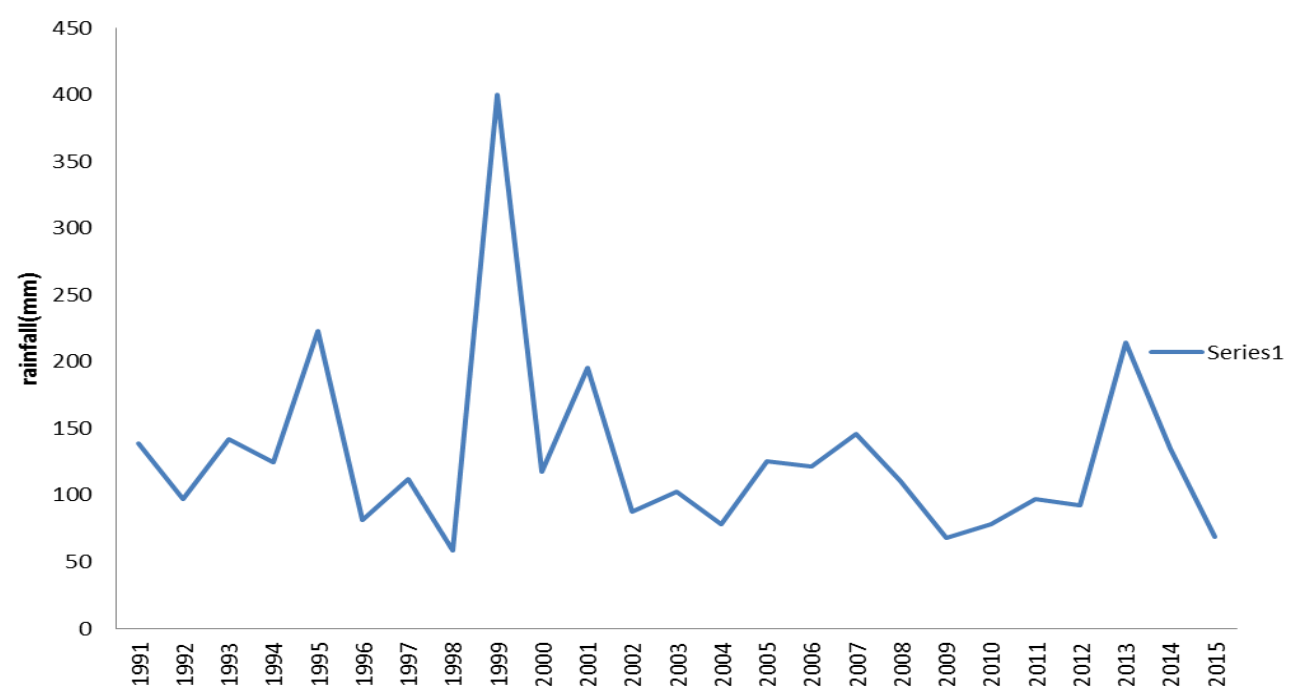

Fig.1 Maximum one day rainfall for the period of 1991-2015

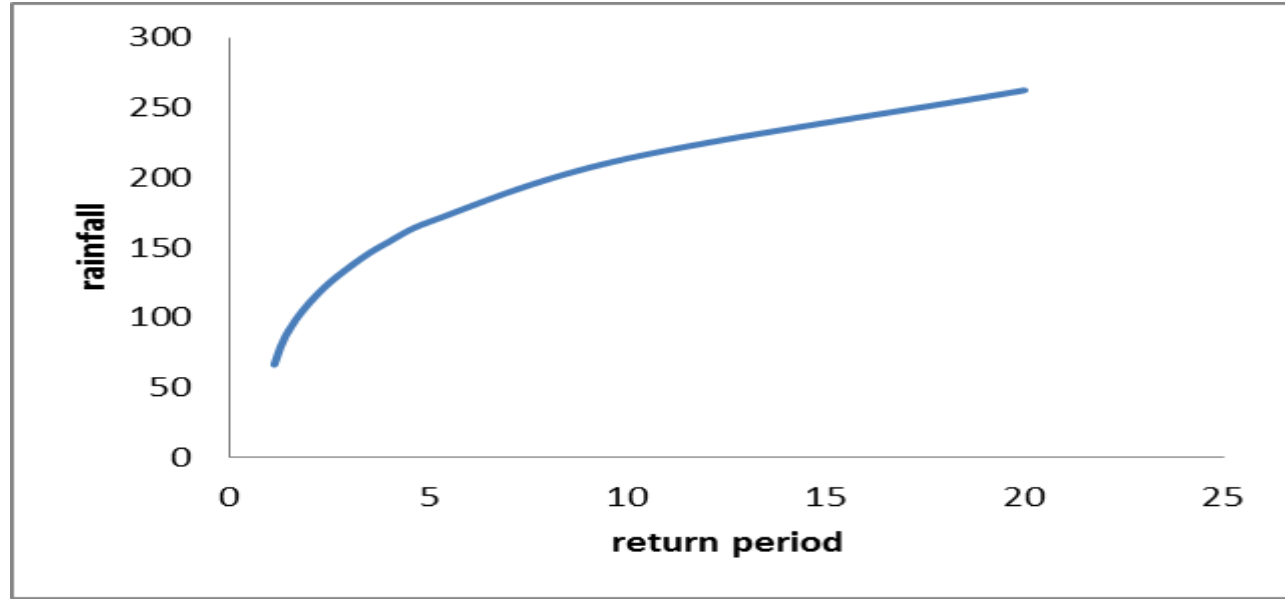

Fig.2 Graph between rainfall and return period using log normal 3-parameter distribution

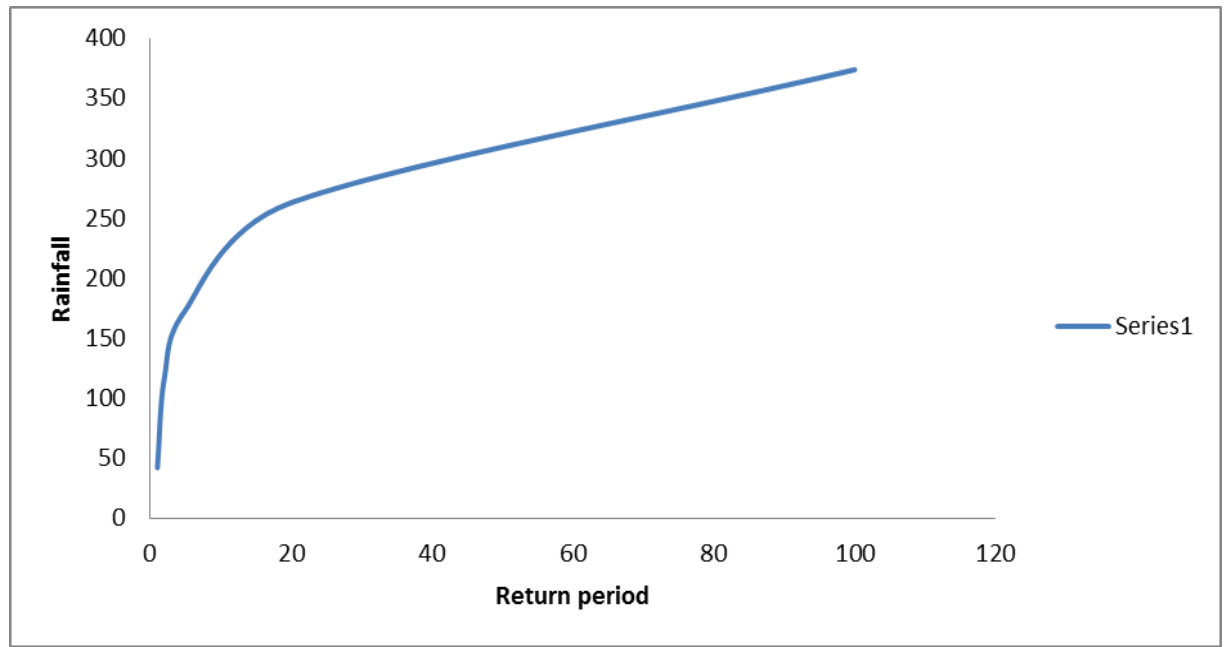

Fig.3 Graph between rainfall and return period by Gumbel's method 


\section{Analysis by Gumbel's method}

Referring the table-7 a graph is plotted between rainfall and return period and the equation is given below:

Regression model was developed from the estimated one day maximum rainfall for different return periods by Gumbel's method and it appeared that the logarithmic trend line had the better coefficient of determination $\left(R^{2}=0.9939\right)$.

The developed model was found to be

$Y=69.782 \ln (x)+55.367$

Where,

$\mathrm{Y}=$ one day maximum precipitation, $\mathrm{mm}$

$\mathrm{X}=$ return period, year

Using above equation the expected maximum one day rainfall for different return periods for the study area is shown in the table 8 . The expected maximum one day rainfall for 50 and 100 years return period is 328.35 and $376.72 \mathrm{~mm}$ respectively. A maximum of $103.73 \mathrm{~mm}$ rainfall is expected to occur at every 2 years (Table 8). It is generally recommended that 2-100 years is sufficient return period for soil and water conservation measures, construction of dams, irrigation and drainage works.

\section{Probable maximum rainfall for design of different structures}

The designed rainfall for different structures is estimated by following equation no 1 and 2 obtained by the two methods i.e chow equation and log normal 3-parameter equation considering the life period .The values are given in table 9 .

It is found from the table that the probable maximum one day rainfall estimated by the two methods is very close to each other. The probability analysis for maximum one day rainfall of Khurda region is done by different probability distribution methods (log normal 3-parameter, Pearson method, log Pearson, Weibull, generalized Pareto distribution and log normal) by taking the rainfall data of 25 years(1991-2015).

Amongst them, log-normal 3-parameter method was found to be best fit based on chisquare and RMSE values (4.5 and 0.03328 respectively). The plotted position of maximum one day precipitation was also tested through Chow method. Frequency factor is calculated by using skewness coefficient, coefficient of variation and frequency factor. The designed return period is calculated through Gumbel's equation.

The designed probable maximum one day rainfall for different soil and water conservation structures was found out. The values are calculated and are given in the table below table no. 10 .

The values of maximum precipitation by lognormal 3-parameter method and Chow frequency factor method are very close to each other and from these two methods, either can be implemented for design of different soil and water conservation structures.

\section{References}

Bhakar, S.R., Bansal, A.K., Chhajed, N. and Purohit, R.C., 2006. Frequency analysis of consecutive days maximum rainfall at Banswara, Rajasthan, India. ARPN Journal of Engineering and Applied Sciences, 1(3), pp.64-67.

Bhargava, P.N., Pradhan, A. and Das, M.N., 1974. Influence of rainfall on crop production. JNKVV Res J Jarwaharlal Nehru Krishi Vishwa Vidylaya.

Chow, V.T., 1951. A general formula for 
hydrologic frequency analysis. Eos, Transactions American Geophysical Union, 32(2), pp.231-237.

Collier, C.G. and Hardaker, P.J., 1996. Estimating probable maximum precipitation using a storm model approach. Journal of hydrology, 183(3-
4), pp.277-306.

Singh, B., Prakash, S. and Singh, J., 2014. Estimation of probable maximum precipitation for one day duration in Jhalarapatan region of Rajasthan. Indian Journal of Soil Conservation, 42(2), pp.130-134.

\section{How to cite this article:}

Geetanjali Dhupal and Sidhartha Sekhar Swain. 2020. Estimation of Probable Maximum One Day Duration Rainfall for Khurda Region. Int.J.Curr.Microbiol.App.Sci. 9(05): 2450-2462. doi: https://doi.org/10.20546/ijcmas.2020.905.281 